\title{
Allopurinol inhibits excess glucose-induced trophoblast IL-1ß and ROS production
}

\author{
Masaru Negi ${ }^{1}$, Melissa J Mulla², Christina S Han² and Vikki M Abrahams ${ }^{1}$ \\ ${ }^{1}$ Department of Obstetrics, Gynecology and Reproductive Sciences, Yale School of Medicine, Yale University, New \\ Haven, Connecticut, USA and ' Department of Obstetrics and Gynecology, David Geffen School of Medicine at \\ UCLA, Los Angeles, California, USA
}

Correspondence should be addressed to V M Abrahams; Email: vikki.abrahams@yale.edu

\begin{abstract}
Pre-gestational diabetes is a risk factor for preeclampsia, a condition associated with inflammatory markers, a dysregulated angiogenic profile, and impaired placentation. Using an in vitro model, we previously reported that hyperglycemic levels of glucose induced a pro-inflammatory (IL-1 $\beta$, IL-8, RANTES, GRO- $\alpha$ ), anti-angiogenic (sFlt-1) and anti-migratory profile in a human trophoblast cell line. The IL-1及 response to excess glucose was mediated by uric acid-induced activation of the NLRP3 inflammasome. Allopurinol is a xanthine oxidase inhibitor that inhibits uric acid and reactive oxygen species (ROS) production. Thus, we sought to test the effects of allopurinol on the IL-1 $\beta$ and other inflammatory, angiogenic and migratory responses that are triggered in the trophoblast by excess glucose. Under excess glucose conditions, allopurinol significantly inhibited trophoblast secretion of inflammatory IL-1 $\beta$; caspase-1 activity; IL-8; RANTES; and GRO- $\alpha$. Allopurinol also significantly inhibited excess glucose-induced trophoblast secretion of anti-angiogenic sFIt-1. The presence of IL1 Ra significantly inhibited excess glucose-induced trophoblast IL-8 and GRO- $\alpha$ secretion but had no effect on RANTES or sFlt-1. Conversely, DPI, a ROS inhibitor, significantly inhibited excess glucose-induced trophoblast GRO- $\alpha$ and sFIt-1 secretion, but had no effect on IL-8 or RANTES. Together, our findings indicate that the xanthine oxidase inhibitor

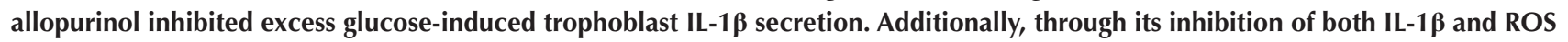
production by the trophoblast, allopurinol reduced the additional pro-inflammatory and anti-angiogenic responses to excess glucose. Thus, allopurinol may be a candidate medication to prevent placental dysfunction and adverse pregnancy outcomes, such as preeclampsia, in pregnant women with diabetes.

Reproduction (2020) 159 73-80
\end{abstract}

\section{Introduction}

Diabetes affected 422 million people worldwide in 2014 and rates continue to increase (World Health Organization 2016). Diabetes affects $2-10 \%$ of pregnant women (Holmes et al. 2011) and during pregnancy it is a risk factor for both maternal and fetal morbidity, including preeclampsia, abnormal fetal growth, and fetal teratogenicity (Sibai et al. 2000, Temple et al. 2006, Holmes et al. 2011). The risk of preeclampsia is increased from the baseline rate of $3.4 \%$ to $11-36 \%$ in the presence of pre-gestational diabetes (Ballas et al. 2012, Ananth et al. 2013, Cohen et al. 2014, Bartsch et al. 2016). Furthermore, this risk increases with poor glycemic control (Bardenheier et al. 2015).

Preeclampsia is characterized by hypertension, proteinuria, and other end-organ dysfunction including liver and brain. It also has significant association with poor fetal outcomes, including preterm delivery, growth restriction, and fetal demise. While the disease itself manifests in the second and third trimesters, preeclampsia is believed to be caused by placental factors originating early in pregnancy (Sibai et al. 2005). Placentas in pregnancies affected by preeclampsia have increased inflammation marked by increased cytokines and chemokines such as IL-1 $\beta$, IL-6, and IL-8 (Farina et al. 2008, 2011, Lockwood et al. 2008). Preeclamptic placentae also have changes in their angiogenic profile with increased anti-angiogenic s-Flt-1 and sEndoglin (Farina et al. 2008, 2011). Furthermore, there is shallow invasion of the placenta and poor remodeling of the spiral arteries (Brosens et al. 1970, Karumanchi \& Stillman 2006, Harris 2010).

Diabetes in pregnancy is also associated with similar changes in the placenta. Even after controlling for preeclampsia, diabetic placentae exhibit an increased inflammatory profile, (Kuzmicki et al. 2012) antiangiogenic markers, (Cohen et al. 2014) and insufficient remodeling of the spiral arteries (Starikov et al. 2014). However, when both diseases are seen together, this placental dysfunction is further elevated (Cohen et al. 2014).

To better understand the mechanisms by which these placental changes associated with diabetes arise, 
we previously established an in vitro system using first trimester extravillous trophoblasts cells exposed to a normal glucose and excess glucose environment (Han et al. 2015). In this prior study, excess glucose conditions induced a trophoblast pro-inflammatory, anti-angiogenic and anti-migratory profile similar to what had already been reported in vivo (Han et al. 2015). In particular, trophoblast secretion of IL-1 $\beta$ was elevated in this model (Han et al. 2015). IL-1 $\beta$ was of specific interest because of its potent pro-inflammatory properties, of its reported effect on placental dysfunction and its association with fetal growth restriction and poor neonatal neurological outcomes (Amu et al. 2006, Girard et al. 2010, Brien et al. 2017, Nadeau-Vallee et al. 2017). The mechanism by which excess glucose induced trophoblast IL-1 $\beta$ was through endogenous uric acid-mediated activation of the NLRP3 inflammasome pathway (Han et al. 2015). Uric acid is produced in the purine metabolism pathway by xanthine oxidase, an enzyme that converts xanthine or hypoxanthine into uric acid. Xanthine oxidase also acts to produce reactive oxygen species (ROS) in a non-specific manner (Botham \& Mayes 2018).

Pregnant women with diabetes are often treated with insulin, glyburide, or metformin to optimize glycemic control. However, adequate glycemic control during pregnancy is often difficult due to insulin resistance induced by placental hormones. Even if glucose levels are reduced, poor glycemic control early in gestation when placentation is at a critical stage may still impact pregnancy and fetal/neonatal outcomes (Holmes et al. 2011, Bardenheier et al. 2015). Aspirin, a cyclooxygenase inhibitor with anti-inflammatory and antiplatelet properties, has been used to prevent or delay onset of preeclampsia (ACOG Committee Opinion 2019). However, clinical trials revealed only a $10-24 \%$ relative reduction in preeclampsia risk, showing an incomplete response (Henderson et al. 2014). Thus, there is a need to find new approaches for managing pregnant women with hyperglycemia in order to prevent or reduce the incidence of associated complications.

Allopurinol is a xanthine oxidase inhibitor and prevents NLRP3 inflammasome activation by inhibiting uric acid and ROS (Gasse et al. 2009, Hu et al. 2012), and already has clinical applications (Rodwell 2018). Studies in the placenta have focused on the ability of allopurinol to reduce oxidative stress (Kane et al. 2013, Murata et al. 2013), but its ability to reduce inflammation in pregnancy has not been addressed. The objective of this study was to determine whether allopurinol would prevent the trophoblast IL-1 $\beta$ response to excess glucose. In addition we sought to determine whether allopurinol had any effect on other markers of trophoblast inflammation under hyperglycemic conditions, as well as the excess glucose-induced trophoblast antiangiogenic and anti-migratory responses.

\section{Materials and methods}

\section{Reagents}

Sterile $45 \%$ solution of D-glucose was purchased from SigmaAldrich. Allopurinol sodium was purchased from Selleck Chemicals. IL-1 receptor antagonist (IL1Ra) was purchased from R\&D Systems. Diphenyleneiodonium (DPI), a ROS inhibitor, was purchased from Sigma-Aldrich. Allopurinol and DPI were both diluted in water. This vehicle at the dilutions used has no effects on trophoblast function (data not shown).

\section{Trophoblast cell culture and treatment}

An established human first trimester extravillous trophoblast cell line, Sw.71, was used in this study (StraszewskiChavez et al. 2009). These cells exhibit characteristics similar to primary cells (Mulla et al. 2009, 2013, StraszewskiChavez et al. 2009). Since this study utilized a cell line, IRB approval was not required. Trophoblast cells were cultured using a protocol previously established (Han et al. 2015). Cells were maintained in DMEM (Life Technologies) supplemented with $10 \%$ fetal bovine serum (Hyclone), $10 \mathrm{mM}$ Hepes, $1 \mathrm{mM}$ sodium pyruvate, and $100 \mathrm{nM}$ penicillin/streptomycin (Life Technologies) at $37^{\circ} \mathrm{C}$ with $21 \% \mathrm{O}_{2}$ and $5 \% \mathrm{CO}_{2}$. For treatment experiments, cells were cultured in glucose-free, serum-free RPMI media (Life Technologies) with sterile D-glucose added at either $5 \mathrm{mM}$ representing normoglycemia or $10 \mathrm{mM}$ to represent hyperglycemia. Cells were treated with glucose at $5 \mathrm{mM}$ and $10 \mathrm{mM}$ in the presence or absence of either allopurinol sodium at $200 \mu \mathrm{M}$ or $400 \mu \mathrm{M}$; IL1Ra at $1 \mu \mathrm{g} / \mathrm{mL}$; or $\mathrm{DPI}$ at $0.01 \mu \mathrm{M}$. Allopurinol concentrations were chosen based on past studies (Raijmakers et al. 2004) and were selected after testing for cell viability using the CellTiter $96^{\mathrm{TM}}$ viability assay (Promega) (data not shown). This dosage is, however, higher than that seen in serum, but the concentration at the level of the placenta is unknown (Pharmacists 2009). After $72 \mathrm{~h}$, cellfree supernatants were collected and centrifuged at $1500 \mathrm{~g}$ for $10 \mathrm{~min}$ and stored at $-80^{\circ} \mathrm{C}$ until analysis.

\section{Analysis of secreted trophoblast factors}

Analysis of supernatants was performed by ELISA for the following inflammatory cytokines/chemokines: IL-1 $\beta$, IL-8, IL-6, RANTES, and GRO- $\alpha$; and the anti-angiogenic factor sFlt-1 (R\&D Systems). Caspase-1 activity was analyzed using the Caspase-Glo 1 Inflammasome Assay (Promega).

\section{Trophoblast migration}

Trophoblast cell migration was measured using a previously described two-chamber colormetric assay (EMD Millipore) (Mulla et al. 2010, Gysler et al. 2016).

\section{Statistical analysis}

All experiments were performed at least three times and were assayed in duplicate. Data are reported as mean \pm S.E.M. Statistical significance was set at $P<0.05$ and analysis was 
performed using Prism Software (Graphpad, Inc.). For normally distributed data, significance was determined using a $t$-test. For data not normally distributed, significance was determined using the Wilcoxon matched-pairs signed-rank test.

\section{Results}

\section{Allopurinol inhibits excess glucose-induced trophoblast inflammasome activity and IL-1及 production}

As shown in Fig. 1A excess glucose (10 mM) significantly increased trophoblast secretion of IL-1 $\beta$ to $135.2 \pm 10.6$ $\mathrm{pg} / \mathrm{mL})$ when compared to glucose at $5 \mathrm{mM}(34.0 \pm 4.4$ $\mathrm{pg} / \mathrm{mL}$ ). This was significantly inhibited by allopurinol at $200 \mu \mathrm{M}$ (allo 200) to $109.7 \pm 9.7 \mathrm{pg} / \mathrm{mL}$ and by allopurinol at $400 \mu \mathrm{M}$ (allo 400 ) to $87.3 \pm 10.2 \mathrm{pg} / \mathrm{mL}$. To determine whether the inhibition of excess glucoseinduced trophoblast IL-1 $\beta$ was a result of allopurinol inhibiting inflammasome function, caspase-1 activity (Heim et al. 2018) was measured. As shown in Fig. $1 \mathrm{~B}$, excess glucose significantly increased trophoblast caspase-1 activity to $78.0 \pm 3.7$ RLU when compared to glucose at $5 \mathrm{mM}(54.9 \pm 3.7 \mathrm{RLU})$, and this was significantly inhibited by allopurinol at $400 \mu \mathrm{M}$ to $53.9 \pm 3.1$ RLU. Allopurinol at $200 \mu \mathrm{M}$ had no effect on trophoblast caspase- 1 activity under excess glucose conditions. However, both doses of allopurinol significantly reduced trophoblast caspase- 1 activity under $5 \mathrm{mM}$ glucose conditions (Fig. 1B).

\section{Allopurinol inhibits excess glucose-induced trophoblast inflammation}

To determine whether allopurinol modulated any other trophoblast inflammatory responses to excess glucose, trophoblast secretion of IL-8, RANTES, GRO $\alpha$ and IL-6 were measured. As shown in Fig. 2, allopurinol at 400 $\mu \mathrm{M}$ significantly inhibited excess glucose-induced (A) IL-8 from $77348.2 \pm 9659.0$ to $44190.5 \pm 2510.0 \mathrm{pg} / \mathrm{mL}$; (B) RANTES from $1024.3 \pm 129.9$ to $638.0 \pm 108.8$ $\mathrm{pg} / \mathrm{mL}$; and (C) GRO $\alpha$ from $36957.8 \pm 2063.0$ to $26063.2 \pm 3401.0 \mathrm{pg} / \mathrm{mL}$. Allopurinol at $200 \mu \mathrm{M}$ also significantly inhibited excess glucose-induced (B) RANTES to $803.1 \pm 112.2 \mathrm{pg} / \mathrm{mL}$ and (C) GRO $\alpha$ to $28074.0 \pm 1409.0 \mathrm{pg} / \mathrm{mL}$ (Fig. 2). Excess-glucoseinduced IL-6 secretion by the trophoblast was not affected by allopurinol at either doses (Fig. 2D).

\section{Allopurinol inhibits the excess glucose-induced trophoblast anti-angiogenic response.}

Having found that allopurinol inhibited trophoblast inflammatory responses to excess glucose, we next sought to determine whether the anti-angiogenic and anti-migratory responses could also be modulated. Excess glucose induced sFlt-1 release by the trophoblast
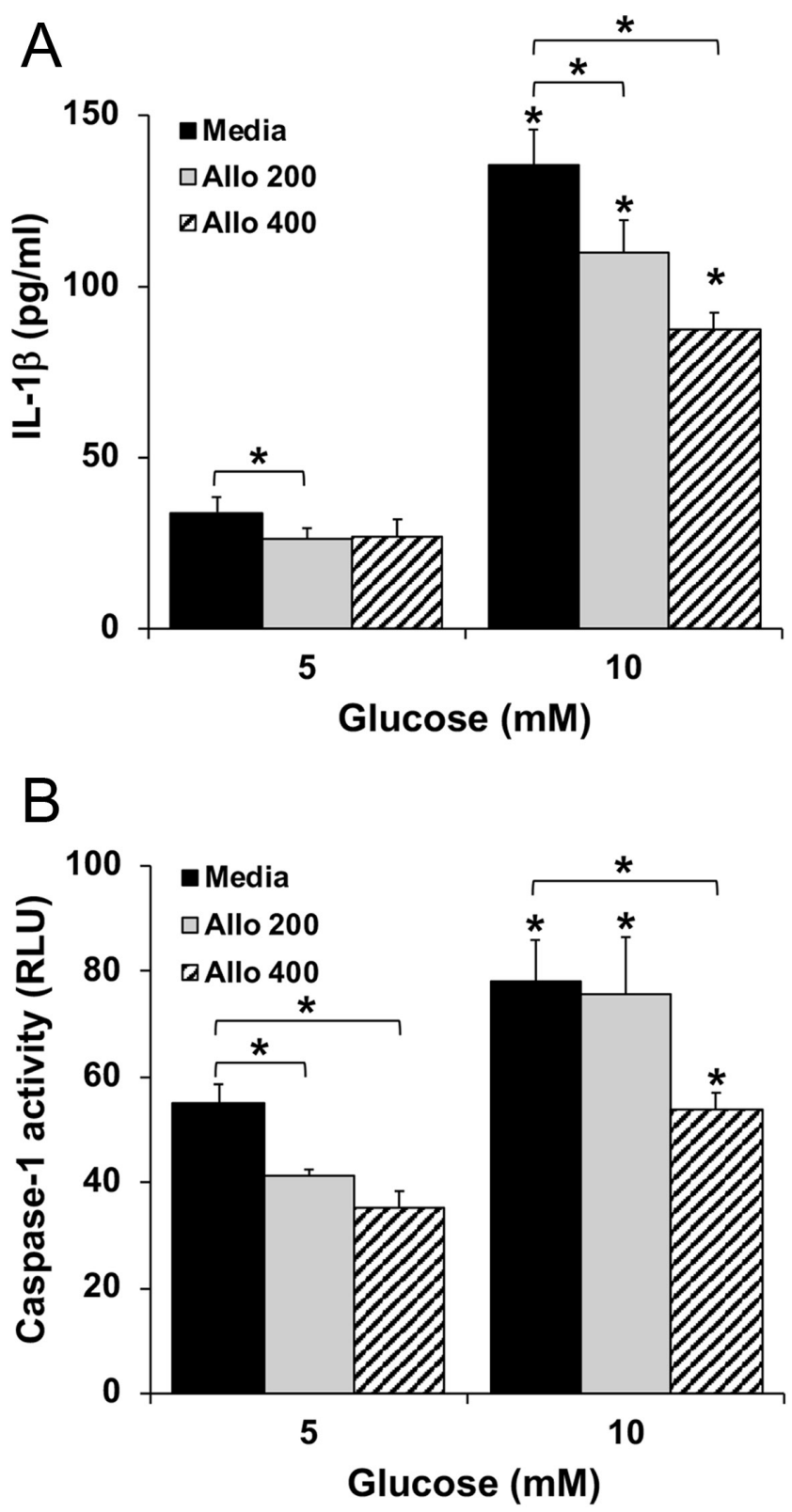

Figure 1 Effect of allopurinol (allo) on the excess glucose-induced trophoblast inflammasome response. Barcharts show (A) secreted IL-1 $\beta$ levels and (B) caspase- 1 activity $(n=7) . * P<0.05$ when compared to $5 \mathrm{mM}$ glucose unless otherwise indicated.

$(3699.7 \pm 315.1 \mathrm{pg} / \mathrm{mL})$ was significantly inhibited by allopurinol at $200 \mu \mathrm{M}$ to $3124.9 \pm 239.4 \mathrm{pg} / \mathrm{mL}$ and at $400 \mu \mathrm{M}$ to $2738.4 \pm 127.3 \mathrm{pg} / \mathrm{mL}$ (Fig. 3A). Allopurinol at both doses had no effect on the ability of excess glucose to reduce trophoblast migration (Fig. 3B).

\section{Allopurinol modulates trophoblast responses to excess glucose by inhibiting IL-1及 and ROS production}

Since we found that allopurinol inhibited not only the $\mathrm{IL}-1 \beta$ response to excess glucose but also the 

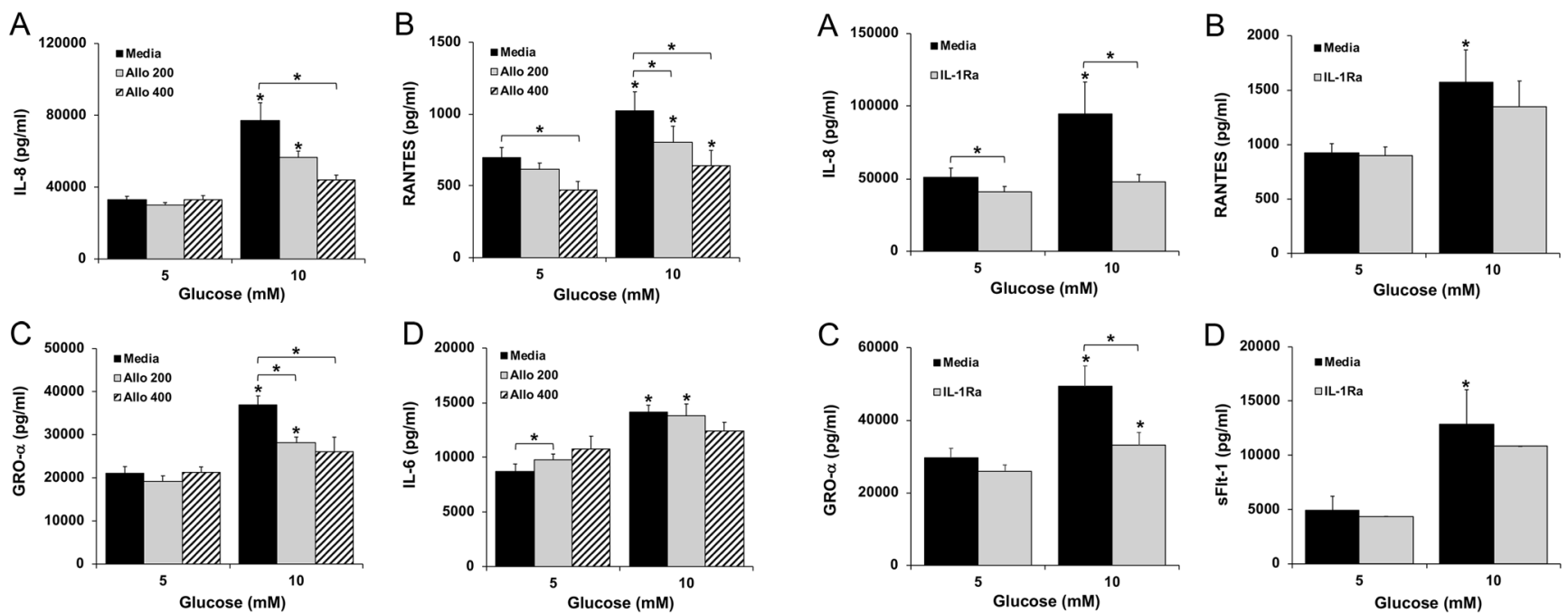

Figure 2 Effect of allopurinol on the excess glucose-induced trophoblast inflammatory response. Barcharts show secreted levels of (A) IL-8; (B) RANTES; (C) GRO- $\alpha$; and (D) IL-6 $(n=17)$. ${ }^{*} P<0.05$ when compared to $5 \mathrm{mM}$ glucose unless otherwise indicated.

induction of other inflammatory and anti-angiogenic factors, we sought to understand the mechanisms involved. Allopurinol inhibits xanthine oxidase to prevent uric acid-induced IL-1 $\beta$ production. Therefore, one possibility is that IL-1 $\beta$ through activation of the IL-1 receptor mediates these downstream effects (Li et al. 2009). Alternatively, since xanthine oxidase is also involved in the production of ROS in many tissues (Paravicini \& Touyz 2008, Ogura et al. 2015, He et al. 2016, Souza et al. 2017, Schmidt et al. 2019), allopurinol may inhibit the trophoblast inflammatory and anti-angiogenic response to hyperglycemia by preventing ROS production and signaling. To test this, cells were treated with excess glucose in the presence of either IL-1Ra to inhibit the feed-forward activity of IL-1 $\beta$ (Brien et al. 2017) or the ROS inhibitor DPI. As shown in Fig. 4, IL-1Ra significantly inhibited excessglucose-induced trophoblast secretion of (A) IL-8 from $94470.0 \pm 22117.0$ to $48131.3 \pm 4756.0 \mathrm{pg} / \mathrm{mL}$, and
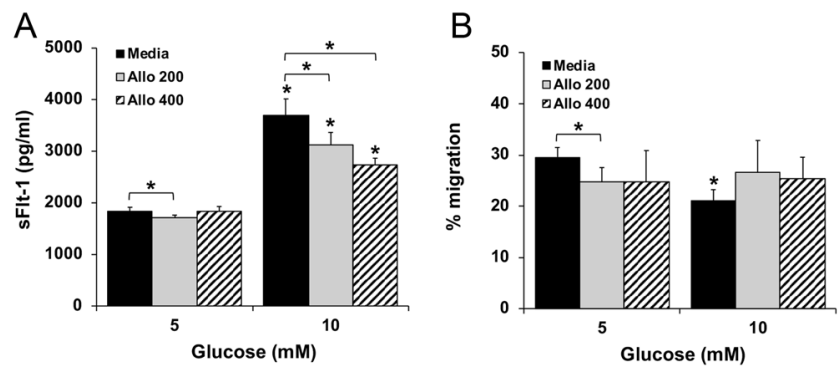

Figure 3 Effect of allopurinol on the excess glucose-induced trophoblast anti-angiogenic and anti-migratory responses. Barcharts show secreted levels of (A) sFlt-1 $(n=7)$ and (B) levels of trophoblast migration $(n=5) . * P<0.05$ when compared to $5 \mathrm{mM}$ glucose unless otherwise indicated.
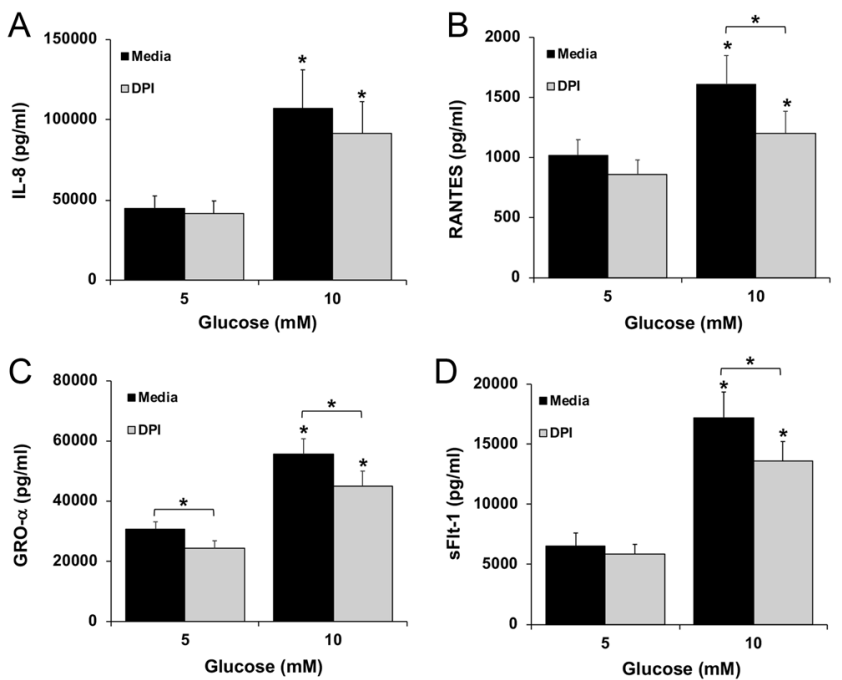

Figure 5 Effect of DPI on the trophoblast inflammatory and antiangiogenic response to excess glucose. Barcharts show secreted levels of (A) IL-8; (B) RANTES; (C) GRO- $\alpha$; and (D) sFlt-1 $(n=7)$. $P<0.05$ when compared to $5 \mathrm{mM}$ glucose unless otherwise indicated. 


\section{Discussion}

Diabetes prior to, and during pregnancy, not only increases the risk of pregnancy complications such as preeclampsia, IUGR and preterm birth, but also increases the risk for fetal and neonatal morbidity and mortality (Ray et al. 2001, Balsells et al. 2009, Teramo 2010, Spiegler et al. 2013, Bardenheier et al. 2015). As the rate of diabetes is rising worldwide, the rate of diabetes in pregnancy is also rising (WHO 2016, Lawrence et al. 2008, Peterson et al. 2015, Britton et al. 2018). This raises the proportion of pregnancies that are at increased risk of preeclampsia to as high as $15-50 \%$ (Siddiqi et al. 1991, Peterson et al. 2015). Preeclampsia can lead to placental abruption, maternal seizures, acute renal dysfunction, acute hepatic failure or hemorrhage, stroke, and death (Sibai et al. 2005). Fetuses are at risk for preterm delivery, growth restriction, hypoxic ischemic encephalopathy, and death (Sibai et al. 2005). Given that the only known cure for preeclampsia is delivery, there is a need for preventative treatment (ACOG Committee Opinion 2019, Sibai et al. 2005). Currently, aspirin is the only accepted preventative medication for preeclampsia which may offer a modest risk reduction of $6-17 \%$ (Bartsch et al. 2016).

Using an in vitro model of hyperglycemia to study trophoblast cell responses to excess glucose, one of the major inflammatory factors produced is IL-1 $\beta$ (Han et al. 2015). Since this IL-1 $\beta$ response was previously found to be mediated by endogenous uric acid-induced NLRP3/ ASC/caspase-1 inflammasome activation (Han et al. 2015), this current study sought to determine the impact of allopurinol, a xanthine oxidase inhibitor, on the trophoblast response to excess glucose. Prior studies in the placenta had focused on the ability of allopurinol to reduce oxidative stress (Kane et al. 2013, Murata et al. 2013), but its ability to reduce inflammation in pregnancy has not been addressed. In this current study, allopurinol was found to inhibit the increased production of trophoblast IL-1 $\beta$ and reduced caspase- 1 activity, suggesting that the mechanism could be by blocking inflammasome function. However, unexpectedly, it was also able to inhibit other inflammatory markers triggered by excess glucose; allopurinol reduced trophoblast secretion of IL-8, RANTES, and GRO- $\alpha$. Mechanistically, our data suggest that trophoblast IL-8 production in response to excess glucose was inhibited by allopurinol preventing the feed-forward mechanism of IL-1 $\beta$ through the IL-1 receptor, given that IL1Ra was able to inhibit trophoblast production of IL-8 while the ROS inhibitor, DPI, did not. Since GRO- $\alpha$ was inhibited by both IL1Ra and DPI, this indicates that allopurinol prevented this trophoblast inflammatory response to excess glucose by inhibiting both the IL-1 $\beta$ mediated feed-forward effect and ROS signaling. While DPI in known to inhibit xanthine oxidase, it can also inhibit other mediators of ROS production (Tazzeo et al. 2009); thus, it is possible that other pathways of ROS generation may be involved. Excess glucose-induced trophoblast RANTES secretion was not altered by either IL1Ra or DPI, suggesting that allopurinol was able to inhibit this trophoblast inflammatory response through a distinct mechanism. While these findings correlate with a previous study showing that uric acid induced IL-1 $\beta$ drives IL-1Rmediated trophoblast inflammation (Brien et al. 2017), there were differences in the factors driven by IL-1R signaling. In our current study we found that excess glucose induced IL-1 $\beta$ promoted trophoblast IL- 8 and GRO- $\alpha$ secretion but not IL- 6 or RANTES, while in the study by Brien et al., trophoblast MCP- 1 and IL- 6 were driven by IL-1 signaling (Brien et al. 2017). However, differences in this study from ours were the use of term cytotrophoblast cells and their direct stimulation with exogenous uric acid (Brien et al. 2017), while our study utilized a first trimester extravillous trophoblast cell in which endogenous uric acid induced IL-1 $\beta$ production.

Allopurinol was also effective at reducing increased trophoblast sFlt-1 production under excess glucose conditions. Mechanistically, unlike the inflammatory markers, production of this anti-angiogenic factor was driven by ROS signaling and not IL- $1 \beta$ given that DPI, but not IL-1Ra, was able to inhibit the sFlt-1 response. While allopurinol did not have an effect on the inhibition of trophoblast migration by excess glucose, given that allopurinol impacted two of the three arms of dysfunction seen in placentas in pregnancies with diabetes (Kuzmicki et al. 2012, Cohen et al. 2014, Starikov et al. 2014), it may still be an effective and uniquely positioned drug for reducing this risk for preeclampsia in this population. Moreover, since allopurinol inhibits two different mechanisms by which trophoblast cytokine/chemokine release was disrupted by excess glucose; by both IL- $1 \beta$ feed-forward and ROS production, inhibiting xanthine oxidase with one drug could may be an efficient way to help prevent placental dysfunction in the context of hyperglycemia.

Allopurinol use in pregnancy as well as studies on its safety in pregnancy are limited. A review by Simsek et al. had 53 subjects with exposure, with two major congenital malformations reported. Both had similar features including cleft lip and palate, auditory canal abnormalities, eye abnormalities, and renal abnormalities. However, the details regarding risk factors for congenital anomalies for both cases were not available, and genetic testing for one case was not performed. The overall rate of malformation was $3.8 \%$, compared to $3-4 \%$ of the general population (Egbe et al. 2015, Persson et al. 2017, Simsek et al. 2018). Therefore, more study is necessary regarding safety of allopurinol in the first trimester. Allopurinol can cross the placenta and its role in providing fetal neuroprotection by preventing oxidative stress has been studied, but in the later stages of pregnancy (Masaoka et al. 2005, Torrance et al. 2009, Kane et al. 
2013, Kaandorp et al. 2014, 2015). Since placental inflammation is linked to prenatal brain injury, with IL-1 $\beta$ being a key mediator (Girard et al. 2012, Leitner et al. 2014, Rosenzweig et al. 2014), preventing hyperglycemia-induced placental inflammation may both protect against pregnancy complications and provide protection against inflammation-induced fetal injury. Strengths of this study are that it was based on an established model of hyperglycemia (Han et al. 2015, Heim et al. 2018) using an immortalized firsttrimester trophoblast cell line shown to have similar response to primary cells (Mulla et al. 2009, 2013, Straszewski-Chavez et al. 2009). It also is the first study to investigate the ability of allopurinol to impact trophoblast responses to excess glucose. Findings are consistent with the known action of allopurinol as a xanthine oxidase inhibitor and the mechanistic findings of this study advance our understanding of how excess glucose induce trophoblast dysfunction. Weaknesses of this study are that it is purely in vitro and uses biochemical markers as a proxy for disease development. While preeclampsia is a complex disease that is not defined by these markers in the clinical setting (2019, Sibai et al. 2005), there are, however, numerous studies showing biochemical profiles of patients and placentas in cases of preeclampsia (Munno et al. 1999, Sibai et al. 2005, Karumanchi \& Stillman 2006, Farina et al. 2008, 2011, Harris 2010, Kuzmicki et al. 2012, Hara Cde et al. 2016).

In summary, the xanthine oxidase inhibitor allopurinol inhibited excess glucose-induced trophoblast IL-1 $\beta$ secretion. Additionally, through its inhibition of both IL-1 $\beta$ and ROS production by the trophoblast, allopurinol reduced the additional pro-inflammatory and anti-angiogenic responses to excess glucose. Thus, allopurinol might be a potential preventative treatment for preeclampsia in pregnant patients with preexisting diabetes.

\section{Declaration of interest}

The authors declare that there is no conflict of interest that could be perceived as prejudicing the impartiality of the research reported.

\section{Funding}

This work was supported by the Albert McKern Scholar Award (to $\mathrm{V} M \mathrm{~A}$ ).

\section{Author contribution statement}

$\mathrm{VMA}, \mathrm{MN}$ and $\mathrm{C} \mathrm{S} \mathrm{H}$ conceived the study and wrote the paper. $M N$ and $M J M$ performed experiments. $M N$ and $V M$ A analyzed the data.

\section{References}

ACOG Committee Opinion 2019 ACOG Practice Bulletin No. 202: gestational hypertension and preeclampsia. Obstetrics and Gynecology 202 133.e1-133.e25. (https://doi.org/10.1097/ AOG.0000000000003018)

Amu S, Hahn-Zoric M, Malik A, Ashraf R, Zaman S, Kjellmer I, Hagberg H, Padyukov L \& Hanson LA 2006 Cytokines in the placenta of Pakistani newborns with and without intrauterine growth retardation. Pediatric Research 59 254-258. (https://doi.org/10.1203/01. pdr.0000196332.37565.7d)

Ananth CV, Keyes KM \& Wapner RJ 2013 Pre-eclampsia rates in the United States, 1980-2010: age-period-cohort analysis. BMJ 347 f6564. (https:// doi.org/10.1136/bmj.f6564)

Ballas J, Moore TR \& Ramos GA 2012 Management of diabetes in pregnancy. Current Diabetes Reports 12 33-42. (https://doi.org/10.1007/ s11892-011-0249-0)

Balsells M, Garcia-Patterson A, Gich I \& Corcoy R 2009 Maternal and fetal outcome in women with type 2 versus type 1 diabetes mellitus: a systematic review and metaanalysis. Journal of Clinical Endocrinology and Metabolism 94 4284-4291. (https://doi.org/10.1210/jc.2009-1231)

Bardenheier BH, Imperatore G, Devlin HM, Kim SY, Cho P \& Geiss LS 2015 Trends in pre-pregnancy diabetes among deliveries in 19 U.S. states, 2000-2010. American Journal of Preventive Medicine $\mathbf{4 8}$ 154-161. (https://doi.org/10.1016/j.amepre.2014.08.031)

Bartsch E, Medcalf KE, Park AL, Ray JG \& High Risk of Pre-Eclampsia Identification Group 2016 Clinical risk factors for pre-eclampsia determined in early pregnancy: systematic review and meta-analysis of large cohort studies. BMJ 353 i1753. (https://doi.org/10.1136/bmj.i1753)

Botham KM \& Mayes PA 2018 Biologic oxidation. In Harper's Illustrated Biochemistry, 31e. Eds VW Rodwell, DA Bender, KM Botham, PJ Kennelly \& PA Weil. New York, NY: McGraw-Hill Education.

Brien ME, Duval C, Palacios J, Boufaied I, Hudon-Thibeault AA, NadeauVallee M, Vaillancourt C, Sibley CP, Abrahams VM, Jones RL et al. 2017 Uric acid crystals induce placental inflammation and alter trophoblast function via an IL-1-dependent pathway: implications for fetal growth restriction. Journal of Immunology 198 443-451. (https:// doi.org/10.4049/jimmunol.1601179)

Britton LE, Hussey JM, Crandell JL, Berry DC, Brooks JL \& Bryant AG 2018 Racial/ethnic disparities in diabetes diagnosis and glycemic control among women of reproductive age. Journal of Women's Health 27 1271-1277. (https://doi.org/10.1089/jwh.2017.6845)

Brosens IA, Robertson WB \& Dixon HG 1970 The role of the spiral arteries in the pathogenesis of pre-eclampsia. Journal of Pathology 101 Pvi.

Cohen AL, Wenger JB, James-Todd T, Lamparello BM, Halprin E, Serdy S, Fan S, Horowitz GL, Lim KH, Rana S et al. 2014 The association of circulating angiogenic factors and $\mathrm{HbA} 1 \mathrm{c}$ with the risk of preeclampsia in women with preexisting diabetes. Hypertension in Pregnancy 33 81-92. (https://doi.org/10.3109/10641955.2013.837175)

Egbe A, Uppu S, Lee S, Stroustrup A, Ho D \& Srivastava S 2015 Congenital malformations in the newborn population: a population study and analysis of the effect of sex and prematurity. Pediatrics and Neonatology 56 25-30. (https://doi.org/10.1016/j.pedneo.2014.03.010)

Farina A, Sekizawa A, De Sanctis P, Purwosunu Y, Okai T, Cha DH, Kang JH, Vicenzi C, Tempesta A, Wibowo $\mathbf{N}$ et al. 2008 Gene expression in chorionic villous samples at 11 weeks' gestation from women destined to develop preeclampsia. Prenatal Diagnosis 28 956-961. (https://doi. org/10.1002/pd.2109)

Farina A, Zucchini C, De Sanctis P, Morano D, Sekizawa A, Purwosunu Y, Okai T \& Rizzo N 2011 Gene expression in chorionic villous samples at 11 weeks of gestation in women who develop pre-eclampsia later in pregnancy: implications for screening. Prenatal Diagnosis 31 181-185. (https://doi.org/10.1002/pd.2675)

Gasse P, Riteau N, Charron S, Girre S, Fick L, Petrilli V, Tschopp J, Lagente V, Quesniaux VF, Ryffel B et al. 2009 Uric acid is a danger signal activating NALP3 inflammasome in lung injury inflammation and fibrosis. American Journal of Respiratory and Critical Care Medicine 179 903-913. (https://doi.org/10.1164/rccm.200808-1274OC)

Girard S, Tremblay L, Lepage M \& Sebire G 2010 IL-1 receptor antagonist protects against placental and neurodevelopmental defects induced by maternal inflammation. Journal of Immunology 184 3997-4005. (https:// doi.org/10.4049/jimmunol.0903349) 
Girard S, Sebire H, Brochu ME, Briota S, Sarret P \& Sebire G 2012 Postnatal administration of IL-1RA exerts neuroprotective effects following perinatal inflammation and/or hypoxic-ischemic injuries. Brain, Behavior, and Immunity 26 1331-1339. (https://doi.org/10.1016/j. bbi.2012.09.001)

Gysler SM, Mulla MJ, Guerra M, Brosens JJ, Salmon JE, Chamley LW \& Abrahams VM 2016 Antiphospholipid antibody-induced miR-146a-3p drives trophoblast interleukin-8 secretion through activation of toll-like receptor 8. Molecular Human Reproduction 22 465-474. (https://doi. org/10.1093/molehr/gaw027)

Han CS, Herrin MA, Pitruzzello MC, Mulla MJ, Werner EF, Pettker CM, Flannery CA \& Abrahams VM 2015 Glucose and metformin modulate human first trimester trophoblast function: a model and potential therapy for diabetes-associated uteroplacental insufficiency. American Journal of Reproductive Immunology 73 362-371. (https://doi.org/10.1111/ aji.12339)

Hara Cde, C Hara Cde C, França EL, Fagundes DL, de Queiroz AA, Rudge MV, Honorio-França AC \& Calderon Ide M 2016 Characterization of natural killer cells and cytokines in maternal placenta and fetus of diabetic mothers. Journal of Immunology Research 20167154524. (https://doi.org/10.1155/2016/7154524)

Harris LK 2010 Review: trophoblast-vascular cell interactions in early pregnancy: how to remodel a vessel. Placenta 31 (Supplement) S93-S98. (https://doi.org/10.1016/j.placenta.2009.12.012)

He F, Li J, Liu Z, Chuang CC, Yang W \& Zuo L 2016 Redox mechanism of reactive oxygen species in exercise. Frontiers in Physiology 7 486-486. (https://doi.org/10.3389/fphys.2016.00486)

Henderson JT, Whitlock EP, O'Connor E, Senger CA, Thompson JH \& Rowland MG 2014 Low-dose aspirin for prevention of morbidity and mortality from preeclampsia: a systematic evidence review for the U.S. Preventive Services Task Force. Annals of Internal Medicine $\mathbf{1 6 0}$ 695-703. (https://doi.org/10.7326/M13-2844)

Heim KR, Mulla MJ, Potter JA, Han CS, Guller S \& Abrahams VM 2018 Excess glucose induce trophoblast inflammation and limit cell migration through HMGB1 activation of toll-like receptor 4. American Journal of Reproductive Immunology $\mathbf{8 0}$ e13044. (https://doi.org/10.1111/ aji.13044)

Holmes VA, Young IS, Patterson CC, Pearson DW, Walker JD, Maresh MJ, McCance DR \& Diabetes and Pre-eclampsia Intervention Trial Study Group 2011 Optimal glycemic control, pre-eclampsia, and gestational hypertension in women with type 1 diabetes in the diabetes and preeclampsia intervention trial. Diabetes Care 34 1683-1688.

Hu QH, Zhang X, Pan Y, Li YC \& Kong LD 2012 Allopurinol, quercetin and rutin ameliorate renal NLRP3 inflammasome activation and lipid accumulation in fructose-fed rats. Biochemical Pharmacology $\mathbf{8 4}$ 113-125. (https://doi.org/10.1016/j.bcp.2012.03.005)

Kaandorp JJ, van den Broek MP, Benders MJ, Oudijk MA, Porath MM, Bambang Oetomo S, Wouters MG, van Elburg R, Franssen MT, Bos AF et al. 2014 Rapid target allopurinol concentrations in the hypoxic fetus after maternal administration during labour. Archives of Disease in Childhood: Fetal and Neonatal Edition 99 F144-F148. (https://doi. org/10.1136/archdischild-2013-304876)

Kaandorp JJ, Benders MJ, Schuit E, Rademaker CM, Oudijk MA, Porath MM, Oetomo SB, Wouters MG, van Elburg RM, Franssen MT et al. 2015 Maternal allopurinol administration during suspected fetal hypoxia: a novel neuroprotective intervention? A multicentre randomised placebo controlled trial. Archives of Disease in Childhood: Fetal and Neonatal Edition 100 F216-F223. (https://doi.org/10.1136/ archdischild-2014-306769)

Kane AD, Camm EJ, Richter HG, Lusby C, Tijsseling D, Kaandorp JJ, Derks JB, Ozanne SE \& Giussani DA 2013 Maternal-to-fetal allopurinol transfer and xanthine oxidase suppression in the late gestation pregnant rat. Physiological Reports 1 e00156. (https://doi.org/10.1002/phy2.156)

Karumanchi SA \& Stillman IE 2006 In vivo rat model of preeclampsia. Methods in Molecular Medicine 122 393-399. (https://doi. org/10.1385/1-59259-989-3:393)

Kuzmicki M, Telejko B, Wawrusiewicz-Kurylonek N, Citko A, Lipinska D, Pliszka J, Wilk J, Kalejta K, Lemancewicz A, Grabiec M et al. 2012 The expression of suppressor of cytokine signaling 1 and 3 in fat and placental tissue from women with gestational diabetes. Gynecological Endocrinology 28 841-844. (https://doi.org/10.3109/09513590.2012.6 83055)
Lawrence JM, Contreras R, Chen W \& Sacks DA 2008 Trends in the prevalence of preexisting diabetes and gestational diabetes mellitus among a racially/ethnically diverse population of pregnant women, 1999-2005. Diabetes Care 31 899-904. (https://doi.org/10.2337/dc07-2345)

Leitner, K, Al Shammary, M, McLane, M, Johnston, MV, Elovitz, MA \& Burd I 2014 IL-1 receptor blockade prevents fetal cortical brain injury but not preterm birth in a mouse model of inflammation-induced preterm birth and perinatal brain injury. American Journal of Reproductive Immunology 71 418-426.

Li F, Thiele I, Jamshidi N \& Palsson BØ 2009 Identification of potential pathway mediation targets in toll-like receptor signaling. PLoS Computational Biology 5 e1000292. (https://doi.org/10.1371/journal. pcbi.1000292)

Lockwood CJ, Yen CF, Basar M, Kayisli UA, Martel M, Buhimschi I, Buhimschi C, Huang SJ, Krikun G \& Schatz F 2008 Preeclampsia-related inflammatory cytokines regulate interleukin-6 expression in human decidual cells. American Journal of Pathology 172 1571-1579. (https:// doi.org/10.2353/ajpath.2008.070629)

Masaoka N, Nakajima Y, Hayakawa Y, Ohgame S, Hamano S, Nagaishi M \& Yamamoto T 2005 Transplacental effects of allopurinol on suppression of oxygen free radical production in chronically instrumented fetal lamb brains during intermittent umbilical cord occlusion. Journal of Maternal-Fetal and Neonatal Medicine 18 1-7. (https://doi. org/10.1080/14767050500127716)

Mulla MJ, Yu AG, Cardenas I, Guller S, Panda B \& Abrahams VM 2009 Regulation of Nod1 and Nod2 in first trimester trophoblast cells. American Journal of Reproductive Immunology 61 294-302. (https://doi. org/10.1111/j.1600-0897.2009.00694.x)

Mulla MJ, Myrtolli K, Brosens JJ, Chamley LW, Kwak-Kim JY, Paidas MJ \& Abrahams VM 2010 Antiphospholipid antibodies limit trophoblast migration by reducing IL-6 production and STAT3 activity. American Journal of Reproductive Immunology 63 339-348. (https://doi. org/10.1111/j.1600-0897.2009.00805.x)

Mulla MJ, Salmon JE, Chamley LW, Brosens JJ, Boeras CM, Kavathas PB \& Abrahams VM 2013 A role for uric acid and the Nalp3 inflammasome in antiphospholipid antibody-induced IL-1 beta production by human first trimester trophoblast. PLOS ONE 8 e65237. (https://doi.org/10.1371/ journal.pone.0065237)

Munno I, Chiechi LM, Lacedra G, Putignano G, Patimo C, Lobascio A \& Loizzi P 1999 Spontaneous and induced release of prostaglandins, interleukin (IL)-1 beta, IL-6, and tumor necrosis factor-alpha by placental tissue from normal and preeclamptic pregnancies. American Journal of Reproductive Immunology 42 369-374. (https://doi. org/10.1111/j.1600-0897.1999.tb00114.x)

Murata M, Fukushima K, Takao T, Seki H, Takeda S \& Wake N 2013 Oxidative stress produced by xanthine oxidase induces apoptosis in human extravillous trophoblast cells. Journal of Reproduction and Development 59 7-13. (https://doi.org/10.1262/jrd.2012-053)

Nadeau-Vallee M, Chin PY, Belarbi L, Brien MÈ, Pundir S, Berryer MH, Beaudry-Richard A, Madaan A, Sharkey DJ, Lupien-Meilleur A et al. 2017 Antenatal suppression of IL-1 protects against inflammationinduced fetal injury and improves neonatal and developmental outcomes in mice. Journal of Immunology 198 2047-2062. (https://doi. org/10.4049/jimmunol.1601600)

Ogura J, Kuwayama K, Sasaki S, Kaneko C, Koizumi T, Yabe K, Tsujimoto T, Takeno R, Takaya A, Kobayashi M et al. 2015 Reactive oxygen species derived from xanthine oxidase interrupt dimerization of breast cancer resistance protein, resulting in suppression of uric acid excretion to the intestinal lumen. Biochemical Pharmacology 97 89-98. (https://doi. org/10.1016/j.bcp.2015.06.021)

Paravicini TM \& Touyz RM 2008 NADPH oxidases, reactive oxygen species, and hypertension: clinical implications and therapeutic possibilities. Diabetes Care 31 (Supplement 2) S170-S180. (https://doi. org/10.2337/dc08-s247)

Persson M, Cnattingius S, Villamor E, Söderling J, Pasternak B, Stephansson O \& Neovius M 2017 Risk of major congenital malformations in relation to maternal overweight and obesity severity: cohort study of 1.2 million singletons. BMJ 357 j2563. (https://doi. org/10.1136/bmj.j2563)

Peterson C, Grosse SD, Li R, Sharma AJ, Razzaghi H, Herman WH \& Gilboa SM 2015 Preventable health and cost burden of adverse birth outcomes associated with pregestational diabetes in the United States. 
American Journal of Obstetrics and Gynecology 212 74.e1-74.e9. (https://doi.org/10.1016/j.ajog.2014.09.009)

Pharmacists, ASoHS 2009 AHFS Drug Information Pharmacists. 3691.

Raijmakers MT, Peters WH, Steegers EA \& Poston L 2004 NAD(P)H oxidase associated superoxide production in human placenta from normotensive and pre-eclamptic women. Placenta 25 (Supplement A) S85-S89. (https://doi.org/10.1016/j.placenta.2004.01.009)

Ray JG, O'Brien TE \& Chan WS 2001 Preconception care and the risk of congenital anomalies in the offspring of women with diabetes mellitus: a meta-analysis. Q/M 94 435-444. (https://doi.org/10.1093/ qjmed/94.8.435)

Rodwell VW 2018 Nucleotides. In Harper's Illustrated Biochemistry, 31e. Eds VW Rodwell, DA Bender, KM Botham, PJ Kennelly \& PA Weil. New York, NY: McGraw-Hill Education.

Rosenzweig JM, Lei J \& Burd I 2014 Interleukin-1 receptor blockade in perinatal brain injury. Frontiers in Pediatrics 2 108. (https://doi. org/10.3389/fped.2014.00108)

Schmidt HM, Kelley EE \& Straub AC 2019 The impact of xanthine oxidase (XO) on hemolytic diseases. Redox Biology 21 101072. (https://doi. org/10.1016/j.redox.2018.101072)

Sibai BM, Caritis S, Hauth J, Lindheimer M, VanDorsten JP, MacPherson C, Klebanoff M, Landon M, Miodovnik M, Paul R et al. 2000 Risks of preeclampsia and adverse neonatal outcomes among women with pregestational diabetes mellitus. American Journal of Obstetrics and Gynecology 182 364-369. (https://doi.org/10.1016/s00029378(00)70225-0)

Sibai B, Dekker G \& Kupferminc M 2005 Pre-eclampsia. Lancet 365 785-799. (https://doi.org/10.1016/S0140-6736(05)17987-2)

Siddiqi T, Rosenn B, Mimouni F, Khoury J \& Miodovnik M 1991 Hypertension during pregnancy in insulin-dependent diabetic women. Obstetrics and Gynecology 77 514-519.

Simsek M, Opperman RCM, Mulder CIJ, Lambalk CB \& de Boer NKH 2018 The teratogenicity of allopurinol: a comprehensive review of animal and human studies. Reproductive Toxicology 81 180-187. (https://doi. org/10.1016/j.reprotox.2018.08.012)

Souza CF, Baldissera MD, Moreira KLS, da Rocha MIUM, da Veiga ML, Santos RCV \& Baldisserotto B 2017 Involvement of xanthine oxidase activity with oxidative and inflammatory renal damage in silver catfish experimentally infected with Streptococcus agalactiae: interplay with reactive oxygen species and nitric oxide. Microbial Pathogenesis 111 1-5. (https://doi.org/10.1016/j.micpath.2017.08.010)
Spiegler J, Stichtenoth G, Weichert J, König IR, Schlaud M, V D Wense A, Olbertz D, Gurth H, Schiffmann JH, Bohnhorst B et al. 2013 Pregnancy risk factors for very premature delivery: what role do hypertension, obesity and diabetes play? Archives of Gynecology and Obstetrics 288 57-64. (https://doi.org/10.1007/s00404-013-2739-6)

Starikov R, Inman K, Chen K, Lopes V, Coviello E, Pinar H \& He M 2014 Comparison of placental findings in type 1 and type 2 diabetic pregnancies. Placenta 35 1001-1006. (https://doi.org/10.1016/j. placenta.2014.10.008)

Straszewski-Chavez SL, Abrahams VM, Alvero AB, Aldo PB, Ma Y, Guller S, Romero R \& Mor G 2009 The isolation and characterization of a novel telomerase immortalized first trimester trophoblast cell line, Swan 71. Placenta 30 939-948. (https://doi.org/10.1016/j. placenta.2009.08.007)

Tazzeo T, Worek F \& Janssen Lj 2009 The NADPH oxidase inhibitor diphenyleneiodonium is also a potent inhibitor of cholinesterases and the internal $\mathrm{Ca}(2+)$ pump. British Journal of Pharmacology 158 790-796. (https://doi.org/10.1111/j.1476-5381.2009.00394.x)

Temple RC, Aldridge V, Stanley K \& Murphy HR 2006 Glycaemic control throughout pregnancy and risk of pre-eclampsia in women with type I diabetes. BJOG 113 1329-1332. (https://doi.org/10.1111/j.14710528.2006.01071.x)

Teramo KA 2010 Obstetric problems in diabetic pregnancy - the role of fetal hypoxia. Best Practice and Research: Clinical Endocrinology and Metabolism 24 663-671. (https://doi.org/10.1016/j.beem.2010.05.005)

Torrance HL, Benders MJ, Derks JB, Rademaker CM, Bos AF, Van Den Berg P, Longini M, Buonocore G, Venegas M, Baquero H et al. 2009 Maternal allopurinol during fetal hypoxia lowers cord blood levels of the brain injury marker S-100B. Pediatrics 124 350-357. (https://doi. org/10.1542/peds.2008-2228)

WHO 2016 Global Report on Diabetes. Geneva: World Health Organization.

Received 3 September 2019

First decision 14 October 2019

Revised manuscript received 29 October 2019

Accepted 7 November 2019 